\title{
A produção de jogos eletrônicos por crianças: narrativas digitais e o RPG Maker
}

Dulce Márcia Cruz

Doutora em Engenharia de Produção pela Universidade Federal de Santa Catarina (UFSC). Professora do Centro de Ciências da Educação da UFSC.

E-mail: dulce.marcia@gmail.com

Rafael Marques de Albuquerque

Estudante de PhD no Learning Sciences Research Institute (LSRI) do Centro de Educação da Universidade de Nottingham (Reino Unido). Mestre e Bacharel em Design Gráfico pela UFSC.

E-mail: apenasrafael@yahoo.com.br

Resumo: Este artigo descreve a utilização do software RPG Maker 2003 em uma ação interdisciplinar de trabalho com mídias em uma escola particular. A proposta de atividade foi a de planejar e desenvolver um jogo eletrônico. O RPG Maker 2003 mostrou-se um software de fácil aprendizagem para a construção de narrativas, oferecendo recursos que possibilitam desenvolver jogos diversificados e interessantes. A experiência foi proveitosa na abordagem de mídia-educação.

Palavras-chave: jogos eletrônicos, escola, mídia-educação, RPGMaker, criação de jogos.
Abstract: This paper describes the application of the software RPG Maker 2003 in an interdisciplinary action working with media developed in a private school. The proposed activity was the planning of an electronic game. The RPG Maker 2003 is a software easy to use and to construct narratives, offering resources to develop diversified and interesting games. The experience was successful in the mediaeducation approach.

Keywords: electronic hames, school, mediaeducation, RPGMaker, game development.

\section{INTRODUÇÃO}

Este artigo descreve e analisa as ações e os resultados de uma oficina de criação de jogos eletrônicos realizada em 2010 com crianças na faixa etária de 11 a 12 anos. A oficina foi inserida em um projeto extracurricular de uma escola particular de Florianópolis que já visava a criação de mídias pelos alunos.

A oficina faz parte de um projeto que tem por objetivo explorar as características dos jogos eletrônicos e suas possibilidades pedagógicas, analisando o 
1. GIRARDELLO, G. Produção cultural infantil diante da tela da TV à internet. In: FANTIN, M. GIRARDELLO, G. (orgs.). Liga, roda, clica: estudos em mídia, cultura e infância. Campinas: Papirus, 2008, p. 137.

2. MURRAY, Janet. Hamlet no Holodeck: o futuro da narrativa no ciberespaço. São Paulo: Itaú Cultural/Unesp, 2003.

3. TUFTE, B.; CHRISTENSEN, O. Mídia-educação: entre a teoria e a prática. Perspectiva, Florianópolis, v. 27, n. 1, jan./jun. 2009, pp. 97-118.

4. FANTIN, M. Mídia-educação: conceitos; experiências; diálogos Brasil-Itália. Florianópolis: Cidade Futura, 2006.

5. Idem, pp. 85-86.

6. Idem, p. 86.

7. BUCKINGHAM, D. Media Education: Literacy, Learning and Contemporary Culture. Cambridge: Polity Press, 2003. modo como os jogadores interagem e narram as histórias geradas pelo jogar na escola, assim como as habilidades e os novos modos de aprender desenvolvidos a partir dessas experiências. O foco do trabalho não é o jogo utilizado em si, mas a possibilidade que ele traz de produção de roteiros ou, mais especificamente, de narrativas.

Identificamos as narrativas que investigamos com o que Girardello ${ }^{1}$ chama de "brincadeira narrativa", ou de "verbalização de um faz de conta diante da tela”, uma atividade onde a criança solta sua imaginação criativa e narra histórias conforme interage com o computador. No nosso estudo, essa brincadeira narrativa acontece sob a forma de comentários (orais ou escritos) feitos (para si ou para outros pares) durante o ato de jogar pelo jogador. Identificamos narrativas durante o próprio desenrolar das histórias audiovisuais que são construídas conforme o jogador vai fazendo escolhas e traçando suas trajetórias nos jogos, no que Murray² chamava de "multinarrativas".

Narrativa também tem neste projeto a conotação de produção de histórias, de forma consciente e planejada, que ocorre a partir da apropriação da linguagem hipermidiática do jogo eletrônico e que pode ser o resultado do que muitos autores chamam de educação para a alfabetização midiática ${ }^{3}$ ou letramento digital ${ }^{4}$. Esse aspecto prático e produtivo de histórias é fundamental para entender a proposta descrita aqui, de uma oficina de design de jogos eletrônicos (JE) para crianças na linha das pesquisas da mídia-educação.

\section{REVISÃO TEÓRICA}

Fantin $^{5}$ define a mídia-educação "como um campo aberto de pesquisa e ação em relação às mídias e à educação a partir de um estatuto epistemológico situado na articulação da interface da educação e comunicação". Segundo a autora, a mídia-educação se manifesta como "prática social e disciplina, discurso e intervenção, ação e reflexão, leveza e rigor, ativismo e estratégia, criação e experimentação" ${ }^{6}$ e outras possibilidades que podem surgir.

Fantin destaca os contextos em que a mídia-educação tem se manifestado: metodológico, crítico e produtivo. O contexto metodológico propõe uma visão instrumentalista do uso das mídias como metodologia didática, sendo a mídia-educação uma forma de educação com os meios. O contexto crítico sugere que a mídia-educação atua através da leitura dos produtos midiáticos, buscando a interpretação e a compreensão de seus conteúdos. Realiza-se assim na forma de educação sobre os meios, discutindo o conteúdo neles veiculados, como as ideologias presentes nos jogos eletrônicos e a forma como se organiza sua indústria. $\mathrm{O}$ contexto produtivo, também chamado contexto criativo $^{7}$, defende a mídia-educação como educação através dos meios. Utilizam-se as mídias como linguagem, como forma de expressão e produção. Neste sentido, o contexto produtivo é o mais interessante como proposta educativa, pois inclui os demais, já que, para se criar jogos eletrônicos, é preciso conhecê-los e discuti-los, 
apropriando-se de suas características (imagem, som, gênero, linguagem etc.) e o modo como são constituídas e integradas ao jogo. Isso porque, segundo Belloni $^{8}$, a escola é o locus privilegiado para a inserção da mídia-educação ao possibilitar a abordagem das diferentes mídias por meio das disciplinas escolares, promovendo a formação crítica dos alunos para os meios.

O contexto criativo/produtivo gerou investigações envolvendo criação de jogos eletrônicos, entre eles os descritos por Andrew Burn, David Buckingham ${ }^{9}$ e James Durran $^{10}$. Enquanto seu enfoque é o de desenvolver um letramento midiático para com os jogos, desenvolvendo um senso crítico e de design ao colocar os estudantes como criadores, outras experiências enfatizam habilidades desenvolvidas com a criação de jogos digitais. Essas habilidades podem ser o desenvolvimento da escrita e da leitura ${ }^{11}$, baseando-se na ideia de que jogadores se envolvem em ricos contextos de produção e leitura textual em metatextos sobre jogos ${ }^{12}$ (como fóruns, revistas, fanfics), passando pelo desenvolvimento de um senso de sistemas complexos, de jogo e projeto ${ }^{13}$, até o que seria um extremo atual da ideia, onde todo o currículo escolar é baseado na criação de jogos digitais, como no projeto Quest to Learn ${ }^{14}$, coordenado por Katie Salem.

Nosso projeto, nesse contexto, se aproxima mais das propostas ligadas à mídia-educação, em que a sofisticação da relação entre estudante e as mídias é o enfoque do estudo, e não um conteúdo externo. Embora tenhamos trabalhado com um conteúdo educativo para os jogos (ecologia), ele não foi o foco da aprendizagem, como descreveremos a seguir.

\section{METODOLOGIA}

\section{a. A escolha do software}

O RPG Maker 2003 foi o software utilizado na escola. Dentre as razões para essa escolha, podemos citar que o RPG Maker 2003 nos pareceu uma versão mais simples para os alunos aprenderem e por dispor de uma quantia razoável de recursos, ao mesmo tempo em que acreditávamos que os computadores da escola dariam suporte a ele sem prejudicar o desenvolvimento dos jogos (fato que, como veremos adiante, não se confirmou, deixando o RPG Maker 2003 muitas vezes lento para o uso). Outro motivo importante foi que, ao instalar o RPG Maker 2003, incluímos também seu arquivo RTP, um pacote composto por diversos gráficos (cenários, itens, personagens etc.), sons (de magias, de batalhas, de objetos etc.) e músicas. Como esses elementos já vêm prontos para ser inseridos no jogo em produção, a criação do RPG é simples e pode ser mais facilmente aprendida em relação a outros softwares semelhantes. Sendo assim, por possibilitar o início da construção de um jogo eletrônico de forma rápida a partir de um banco de dados razoável, permitindo aos alunos já nas primeiras aulas visualizarem seu jogo em movimento e contendo diversos elementos interativos, e ter suporte dos computadores da escola, escolhemos o software RPG Maker 2003 para o desenvolvimento da oficina.
8. BELLONI, M. L. O que é mídia-educação. Campinas: Autores Associados, 2001.

9. BUCKINGHAM, D.; A. BURN. Game Literacy in Theory and Practice. Journal of Educational Multimedia and Hypermedia, v. 16, n. 3, 2007, pp. 323-349.

10. BURN, A.; J. DURRAN. Media Literacy in Schools: Practice, Production and Progression. Londres: Paul Chapman, 2007.

11. OWSTON, R.; H. WIDEMAN, et al. Computer Game Development as a Literacy Activity. Computers \& Education, n. 53, 2009, pp. 977-989.

12. STEINKUEHLER, C. Massively Multiplayer Online Gaming as a Constellation of Literacy Practices. In: SHELTON, B. E.; WILEY, D. A. The Design and Use of Simulation Computer Games Education. Rotterdam: Sense, 2007, pp. 181-208.

13. ZIMMERMAN, E. Gaming Literacy. Game Design as a Model for Literacy in the 21st century. Harvard Interactive Media Review, v.1, n.1, 2007, pp. 30-35.

14. INSTITUTE OF PLAY. Quest to Learn: A Pioneering Public School in New York City that Offers a Promising New Model for Student Engagement. Disponível em: <www.instituteofplay. org/work/projects/quest-schools/quest-to-learn>. Acesso em: 13 abr. 2013. 
15. GOMES, C. J. S. O aluno como autor de jogos educacionais em computador. Monografia (especialização em Informática na Educação). Universidade Federal do Rio Grande do Sul, Porto Alegre, 2006.

16. DINIZ, R.R.P. Uma trilogia perfeita: RPG Maker XP, educação e adolescentes. Monografia (especialização em Informática na Educação). Universidade Federal do Rio Grande do Sul, Porto Alegre, 2006.

17. MOURA, J. S. Jogos eletrônicos e professores: primeiras aproximações. $4^{\circ}$ Seminário Jogos eletrônicos, educação e comunicação: construindo novas triIhas, Salvador, 2008. Disponível em: <www. comunidadesvirtuais. pro. $\mathrm{br} / \mathrm{seminario}$ /gt.htm>. Acesso em: 5 ago. 2010.
Outros softwares como o Game Maker e o RPG Maker XP já foram anteriormente utilizados em experiências de criação de jogos eletrônicos. Gomes ${ }^{15}$, por exemplo, narra uma oficina em que utilizou o Game Maker com o objetivo de criação de jogos eletrônicos educacionais. Segundo Gomes, os alunos tiveram que se apropriar dos conteúdos escolares que abordaram em seus jogos e que serviram de base para a construção dos seus diversos desafios, cenários, e história e conclui que a criação de jogos eletrônicos na escola pode ser uma forma motivante para o ensino dos mais diversos conteúdos. Diniz ${ }^{16}$ narra que trabalhou com um jogo eletrônico do gênero RPG cujo tema era relacionado com o Brasil (questões históricas, geográficas etc.) utilizando o RPG Maker XP e também conclui que seu uso foi atrativo e motivou o trabalho dos alunos, proporcionando a aprendizagem cooperativa e desenvolvendo sua criatividade e imaginação. Por outro lado, Moura ${ }^{17}$ trabalhou com o RPG Maker XP numa oficina para proporcionar a professores um contato com os jogos eletrônicos. Sua pesquisa apontou que os professores tiveram muita dificuldade por causa do desconhecimento de computadores e de jogos eletrônicos, o que fez com que apenas alguns conseguissem atingir a meta de criar um jogo com o software.

\section{b. As possibilidades do RPG Maker 2003}

O RPG Maker 2003 permite a criação de jogos no estilo RPG com ênfase na narrativa e nas batalhas que levam à evolução dos personagens. Ele permite criar cenários em uma área personalizável dividida em quadrados ou mapas (como um tabuleiro). O personagem principal - aqui chamado de "herói" - se desloca pelo cenário e interage com os chamados "eventos", que são determinados quadrados do cenário que se comportam como se fossem programados. Alguns exemplos de eventos são personagens que conversam com o herói (como uma princesa, que conta ao herói que o tesouro foi roubado), uma batalha (um dragão, que ao ser abordado começa uma cena de combate) ou mudanças diversas (como uma alavanca, que, ao ser utilizada, dispara um comando para abrir a ponte levadiça).

Para a criação do cenário, o jogo oferece uma biblioteca de opções (o chamado RTP), onde são oferecidas imagens prontas de monstros, heróis, e componentes do cenário (florestas, montanhas, paredes, tochas...). A edição do cenário é bastante simples e de fácil aprendizagem. Os eventos são um pouco menos intuitivos, porém, são eles que geram as interações do cenário, que possibilitam movimentos, batalhas, diálogos e acontecimentos em geral. Os comandos dos eventos podem ser simples, desde uma fala (como uma placa que ao ser acionada mostra o texto "cuidado com o pântano!") ou complexos, que só podem ser acionados se determinadas variáveis estiverem cumpridas, ou que geram várias consequências dentro do jogo.

Outro artifício do RPG Maker são os switches (por nós chamados de "interruptores"). Eles funcionam como botões que, quando acionados pelos eventos, mudam outros eventos, ou o próprio. Vale ressaltar que a forma como o 
software disponibiliza os switches não é intuitiva, necessitando de alguns passos para ser concretizado, de forma que foi uma dificuldade da equipe lidar com tal conceito com as crianças.

\section{c. Oficinas}

A oficina se constituiu em 16 encontros com cerca de duas aulas de 50 minutos cada. Trabalhamos com a visão da aprendizagem dos conteúdos procedimentais (CP) no sentido que lhe dá Zabala18 com o que é preciso "saber fazer", ou seja, um conjunto de técnicas, habilidades, destrezas, estratégias que apresentam características comuns. Por essa razão, realizamos a oficina de um modo que pudéssemos trabalhar com as crianças a aprendizagem relacionada às habilidades de produção dos jogos e, ao mesmo tempo, fomos observando e apoiando a aprendizagem dos conteúdos conceituais (o que é preciso "saber") e atitudinais (que admitem "ser") ${ }^{19}$, nos momentos em que pedíamos que refletissem sobre o que estavam realizando.

Para Zabala, a aprendizagem de um CP acontece com a realização de ações e a aplicação em contextos diferenciados. Ele propõe que o ensino dos CPs deve partir de situações significativas e funcionais; estar planejado em forma de progresso e ordem; conter a apresentação de modelos; proporcionar prática orientada e ajudas de diferentes graus e o trabalho independente.

Por essa razão, alguns dos procedimentos utilizados (alternadamente) em sala de aula foram: (i) formulários com vários itens sobre o jogo, inicialmente utilizados como roteiro de análise, que as crianças preenchiam de acordo com as características dos jogos que estavam analisando, e, posteriormente, como roteiro do projeto, colocando na forma de perguntas os itens que deveriam ser definidos no processo de criação do jogo; (ii) clara separação entre o momento de concepção/criação - trabalhávamos em uma sala de aula comum e o objetivo era a redação do projeto do jogo com as ideias das crianças - e o outro momento, de produção, feito na sala de informática, onde o objetivo era desenvolver o jogo proposto no software.

Para a construção dos jogos, a direção da escola sugeriu que trabalhássemos com temas relacionados com a ecologia, presentes no contexto dos alunos que já vinham sendo abordados em um projeto por uma professora que participou integralmente das oficinas.

Foram formados três grupos para a criação do jogo que iremos descrever brevemente abaixo e cuja numeração será utilizada ao longo do artigo para referenciar as equipes de produção:

Grupo 1: formado por quatro crianças do sexo feminino que apresentavam algumas divergências entre si e pouco interesse por jogos eletrônicos.

Grupo 2: formado por quatro crianças do sexo feminino com poucas divergências entre si e muito interesse por jogos eletrônicos.
18. ZABALA, Antoni (org.). Como trabalhar os conteúdos procedimentais em aula. Porto Alegre: Artmed, 1999.

19. COLL, César. Aprendizagem escolar e construção do conhecimento. Porto Alegre: Artmed, 1994. 
Grupo 3: formado por três crianças do sexo masculino e muito interesse em jogos eletrônicos. Um dos membros do grupo não pertencia à turma, mas a uma sala mais avançada do oitavo ano.

A descrição e a análise da experiência que compõe este artigo estão baseadas nas anotações do diário de campo produzido por um dos investigadores a cada aula, pela reflexão da equipe durante o processo e pela gravação de uma entrevista de avaliação feita no final do projeto com cada grupo. Essa entrevista semiestruturada com perguntas elaboradas foi realizada no último dia de aula, no final do semestre. Cada grupo foi entrevistado separadamente e os integrantes falaram livremente sobre cada tópico perguntado.

\section{d. A experiência com o software}

O aprendizado do programa foi sempre diretamente relacionado à prática. Nas primeiras aulas, houve uma centralização das explicações sobre o software nas mãos de um dos pesquisadores, alternando períodos de prática do jogo para conhecimento de algumas funções e aula expositiva. No segundo momento, as crianças podiam criar seus jogos a partir daquilo que fora explicado. Logo nas primeiras aulas, as crianças conseguiram facilmente compreender o funcionamento básico do programa, criando cenários, apesar de não prestarem atenção em detalhes da sua configuração. Conceitos mais complicados, como os eventos, que determinam as interações do personagem com o cenário, e os switches, que determinam mudanças nos eventos, não foram facilmente assimilados. Os eventos básicos foram aprendidos pela maioria das crianças (cerca de 7 dentre os 11) depois de muita repetição e assistência dos pesquisadores, e os switches, aprendidos por poucos no término da oficina (cerca de três ou quatro). O que se observou foi que a motivação para se criar algo no jogo era essencial para o aprendizado.

Os parâmetros de criação e tomada de decisões durante o desenvolvimento dos jogos foram bastante subjetivos. As crianças discutiam seus pontos de vista, mas seus argumentos eram, geralmente, estéticos, e poucas vezes demonstravam estar preocupados com a experiência do jogador. Tal comportamento resultou, no caso do grupo 1, em um investimento de muito tempo na "decoração" do cenário, e somente mais tarde as meninas perceberam que tais itens eram pouco valorizados pelo jogador padrão, que buscava coisas que aconteciam (eventos, combates, desafios etc.). O grupo 2 debruçou-se mais sobre os desafios, mas tanto o grupo 1 quanto o 2 tiveram que apressar-se no final para poder contar suas narrativas, que foram pouco trabalhadas ao longo da produção.

Durante o desenvolvimento, as crianças frequentemente usavam a função do RPG Maker 2003 de testar, alternando entre os modos de edição e de jogo várias vezes para conferir o resultado do que tinham produzido até ali. O teste do jogo era não apenas um forte motivador (as crianças ficavam excitadas quando percebiam suas criações funcionando dentro do jogo), mas também uma forma de descontrair: muitas vezes vários integrantes do mesmo grupo 
queriam ser o testador naquele momento, disputando a função. A possibilidade de alternar facilmente para o modo de jogo nos parece ter sido essencial para que as crianças tivessem se mantido motivadas e compreendendo as consequências das ações criadas dentro do mundo do jogo.

O software RPG Maker 2003 - em especial a parte de criação de cenários, que é simples e intuitiva, já que os jogadores clicam nas estruturas desejadas em uma paleta e depois no local do cenário onde querem que a estrutura esteja - fez com que algumas crianças achassem divertido criar o jogo, usando o software como um jogo em si.

\section{e. Os jogos criados}

Ao final da disciplina, três jogos foram criados, um por cada grupo. Para facilitar, chamaremos de jogo 1, jogo 2 e jogo 3, cada um produzido pelo grupo de número correspondente.

O jogo 1 tratava-se da história de uma maga que morava dentro de um parque florestal. Ao perceber que estavam desmatando as árvores, ela procura um templo, precisando desviar de perigosos lixos tóxicos para alcançá-lo, onde encontra uma poção mágica que restaura as árvores e transforma os lenhadores em animais (tigres e leões).

O jogo 2 contava a história de uma aluna de descendência oriental. Quando o professor a informa sobre o desmatamento da mata ao redor do córrego, ela procura a solução na prefeitura, que lhe explica o que seria necessário para reflorestar a área. A pequena heroína então precisa desviar de vários perigos, como carros e tratores, em busca dos ingredientes: sementes, adubo e ferramentas. Ao juntar tudo, ela refloresta a área próxima ao córrego.

O jogo 3 deveria tratar da história de um guarda-costas contratado para defender as celebridades de um show musical que visava arrecadar fundos para ajudar as causas ecológicas da região. Vencendo os monstros que ameaçavam o show, estariam contribuindo para a preservação do meio ambiente.

\section{f. As narrativas}

Os projetos dos jogos desenvolvidos durante o semestre foram criados em sessões fora do laboratório de informática a partir de formulários que eram preenchidos com os elementos criados para serem incorporados no software a seguir. Esse processo de trabalho gerou narrativas nas versões finais dos jogos que apresentaram características inusitadas. Apesar de o RPG Maker 2003 possibilitar a construção de jogos com narrativas não lineares, onde o herói pode explorar o cenário e escolher seu caminho, estabelecendo diferentes rumos da narrativa, caracterizando-se assim como narrativas multilineares ${ }^{20}$, os três grupos conceberam histórias lineares onde o jogador não tinha diferentes opções, apenas vencia os obstáculos e continuava seguindo em frente com o desenrolar da narrativa.

20. COLL, César. Aprendizagem escolar e construção do conhecimento Porto Alegre: Artmed 1994. 
Esse aspecto nos chamou a atenção, mas não temos elementos para explicar a razão dessa limitação. Como hipóteses, podemos listar alguns dos fatores que podem ter sido responsáveis: (i) o tempo que tiveram para produzir o jogo era limitado, já que uma narrativa multilinear exigiria maior trabalho e planejamento; (ii) as experiências com jogos lineares que utilizaram como referência para a criação; (iii) uma possível dificuldade de crianças dessa faixa etária em planejar uma narrativa que pode variar de acordo com os caminhos que o jogador toma, ou ainda, (iv) uma não valorização da escolha do jogador na narrativa como fator determinante de um jogo divertido ou interessante.

No final da etapa de produção, os jogos ainda não explicitavam qual era sua narrativa, então houve uma sugestão por parte dos professores para que eles prestassem atenção se as histórias estavam sendo contadas pelo jogo e que adiantassem esse aspecto, para que os jogadores de teste pudessem entender a história. Houve então um esforço por parte dos alunos nesse sentido. No entanto, notamos que em nenhum dos três jogos a narrativa se destacou. No jogo 2, mesmo que as crianças tenham pensado uma história e se esforçado por serem coerentes com ela, percebemos um esforço em sinalizar no mapa o caminho onde o herói deveria trilhar para pegar os ingredientes, de forma que o jogador entenderia que caminho seguir mesmo que tivesse ignorado completamente a narrativa e as explicações do que deveria fazer, tornando essas informações dispensáveis.

Mesmo assim, podemos dizer que a narrativa foi valorizada pelo grupo 1 . Em determinado momento havia uma falha no jogo: para prosseguir, a heroína deveria entrar em um redemoinho em um lago. No entanto, não havia pistas indicando que o jogador deveria fazer isso, o que complicaria seu avanço no jogo, já que o grupo percebeu que a tendência seria evitar redemoinhos no mar porque sugerem perigo. As crianças resolveram o problema pela narrativa, colocando uma placa com inscrições que continham um enigma simples, que sugeria que naquele momento o jogador deveria entrar naquilo que parecia perigoso (o redemoinho), em vez de evitá-lo.

Por outro lado, percebemos que as crianças, mesmo sendo capazes de criar narrativas, tiveram grande dificuldade em conceber histórias que fossem coerentes com o andamento do jogo. Os grupos 1 e 3 não conseguiram seguir a história original, pois elas não sugeriram desafios e tiveram que alterar as histórias para que elas estivessem vinculadas à estrutura do jogo. O grupo 2 foi o único que desde o início pensou em como a narrativa funcionaria dentro do jogo e manteve sua história quase inalterada até a versão final.

\section{CONSIDERAÇÕES FINAIS}

A prática descrita neste artigo pareceu enriquecedora para as crianças que experimentaram os dois processos, primeiro o de planejar e depois o de executar um jogo, mesmo que simples. Aprenderam o básico do software RPG Maker 2003, conseguiram criar histórias e desafios dentro do tema e os 
implementaram de acordo com os recursos disponíveis. Puderam se colocar como criadoras de uma mídia interativa pouco trabalhada na escola e interagiram com ela nos três processos propostos por Fantin: 1) metodológico, utilizando o software e os exemplos de jogos como ferramentas utilizadas em sala de aula;

2) crítico, posicionando-se como produtores e discutindo os elementos do jogo, como mostram os depoimentos das crianças: "a gente joga jogos e nunca tinha pensado em como ele [sic] foi feito", e ainda: "agora a gente sabe o trabalho que dá [para] fazer um jogo"; 3) no processo produtivo, desenvolvendo a capacidade e potencialidade dos alunos de produzirem novos jogos (mais bem elaborados, já que agora contavam com alguma experiência) com o software trabalhado em sala de aula.

O RPG Maker 2003 mostrou-se um software que pode ser utilizado como ferramenta pedagógica, mesmo com uma turma com crianças muito jovens (com média de idade próxima de 12 anos). Com a devida mediação de adultos, as crianças conseguiram se expressar; concluir, em dois dos grupos, os jogos; e aprender os mecanismos básicos de sua produção.

Algumas questões poderiam ser mais bem exploradas em pesquisas futuras: como este software poderia ser utilizado em turmas de maior faixa etária, que possivelmente trabalhariam mais focados pela sua maior capacidade de abstração, planejamento mais complexo e compreensão dos procedimentos necessários?; como seria a utilização deste software (e de sua linguagem) em uma escola pública, com diferenças geradas pelo poder aquisitivo mais baixo e provavelmente menor letramento digital de crianças que talvez não estivessem tão familiarizadas com jogos eletrônicos como os alunos desta pesquisa?

Finalmente, a produção de narrativas lineares e não multilineares, como possibilita o RPG Maker 2003, também trouxe um questionamento sobre os motivos e as limitações ainda desconhecidas para a criação de histórias digitais pelas crianças. Talvez uma ênfase nesse aspecto em futuras pesquisas poderia levar a entender se as crianças conseguem ou não, como e por que, criar narrativas mais complexas e interativas nos jogos que produzem. Essa discussão talvez possa gerar uma reflexão com as próprias crianças sobre como produzem histórias com, para e através dos jogos eletrônicos.

\section{REFERÊNCIAS}

BELLONI, M. L. O que é mídia-educação. Campinas: Autores Associados, 2001.

BUCKINGHAM, D. Media Education: Literacy, Learning and Contemporary Culture. Cambridge: Polity Press, 2003.

BUCKINGHAM, D.; A. BURN. Game Literacy in Theory and Practice. Journal of Educational Multimedia and Hypermedia, v. 16, n. 3, 2007.

BURN, A.; J. DURRAN. Media Literacy in Schools: Practice, Production and

Progression. Londres: Paul Chapman Publishing, 2007. 
comunicação \& educação • Ano XIX • número 1 • jan/jun 2014

COLL, César. Aprendizagem escolar e construção do conhecimento. Porto Alegre: Artmed, 1994.

DINIZ, R.R.P. Uma trilogia perfeita: RPG Maker XP, educação e adolescentes. Monografia (especialização em Informática na Educação). Universidade Federal do Rio Grande do Sul, Porto Alegre, 2006.

FALCÃO, L.; NEVES, A. M. Narratologia em jogos digitais. In: Anais do 8. Congresso Brasileiro de Pesquisa e Desenvolvimento em Design. São Paulo, 2008.

FANTIN, M. Mídia-educação: conceitos; experiências; diálogos Brasil-Itália. Florianópolis: Cidade Futura, 2006.

FANTIN, M.; GIRARDELLO, G. (orgs.). Liga, roda, clica: estudos em mídia, cultura e infância. Campinas: Papirus, 2008.

GIRARDELLO, G. Produção cultural infantil diante da tela da TV à internet. In: FANTIN, M.; GIRARDELLO, G. (orgs.). Liga, roda, clica: estudos em mídia, cultura e infância. Campinas: Papirus. 2008.

GOMES, C. J. S. O aluno como autor de jogos educacionais em computador. Monografia (especialização em Informática na Educação). Universidade Federal do Rio Grande do Sul, Porto Alegre, 2006.

INSTITUTE OF PLAY. Quest to Learn: A Pioneering Public School in New York City that Offers a Promising New Model for Student Engagement. Disponível em: <www. instituteofplay.org/work/projects/quest-schools/quest-to-learn>. Acesso em: 13 abr. 2013.

MOURA, J. S. Jogos eletrônicos e professores: primeiras aproximações. $4^{\circ}$ Seminário Jogos eletrônicos, educação e comunicação, Salvador, 2008. Disponível em: <www. comunidadesvirtuais.pro.br/seminario4/gt.htm>. Acesso em: 5 ago. 2010.

MURRAY, Janet. Hamlet no Holodeck: o futuro da narrativa no ciberespaço. São Paulo: Itaú Cultural/Unesp, 2003.

OWSTON, R.; H. WIDEMAN, et al. Computer Game Development as a Literacy Activity. Computers \& Education, n. 53, 2009.

STEINKUEHLER, C. Massively Multiplayer Online Gaming as a Constellation of Literacy Practices. In: SHELTON, B. E.; WILEY, D. A. The Design and Use of Simulation Computer Games Education. Rotterdam: Sense, 2007.

TUFTE, B.; CHRISTEnSEN, O. Mídia-educação: entre a teoria e a prática. Perspectiva, Florianópolis, v. 27, n. 1, jan./jun. 2009.

ZABALA, Antoni (org.). Como trabalhar os conteúdos procedimentais em aula. Porto Alegre: Artmed, 1999.

ZIMMERMAN, E. Gaming Literacy. Game Design as a Model for Literacy in the 21st Century. Harvard Interactive Media Review, v.1, n.1, 2007. 